\title{
The Distribution of Diurnal Sea Surface Warming Events in the Western Sargasso Sea
}

\author{
Peter Cornillon and Lothar Stramma
}

\author{
Graduate School of Oceanography, Unicersity of Rhode Island, Narragansett
}

\begin{abstract}
Large diurnal sea surface warming exceeding $1^{\circ} \mathrm{C}$ is common in the western North Atlantic Ocean and is often of large horizontal extent. These events correlate closely with very light winds and high insolation. In the area investigated, $17^{\circ}-40^{\circ} \mathrm{N}$ and $55^{\circ}-80^{\circ} \mathrm{W}$, the largest warming is found in the western portion of the ridge associated with the Azores-Bermuda high, where the lowest wind speeds are observed. The distribution of warming events shows that the largest number occur between June and August, when insolation is highest and percent cloud cover and wind speed are low. The most probable latitude of warming events moves north from approximately $25^{\circ} \mathrm{N}$ in spring to near $30^{\circ} \mathrm{N}$ in summer, a shift similar to that seen in the minimum of the climatological winds. Local areas have a probability as high as $30 \%$ for diurnal warming in excess of $1{ }^{\circ} \mathrm{C}$ in the summer. The net heat flux into the ocean, calculated by using monthly mean values for low latitudes in the summer, excluding diurnal warming events, is biased consistently high by as much as $5 \mathrm{~W} / \mathrm{m}^{2}$ relative to the same values calculated with warming events included.
\end{abstract}

\section{INTRODUCTION}

Until recently, it was generally assumed that diurnal temperature variations at the sea surface in the open ocean were small. Only a few observations from ships existed of diurnal sea surface temperature (SST) amplitudes in excess of $1^{\circ} \mathrm{C}$ in the open ocean. In August 1974, on a day with low winds, Kaiser [1978] observed in the Bermuda area a surface layer of $3.9 \mathrm{~m}$ depth, which was over $1{ }^{\circ} \mathrm{C}$ warmer than the water below. In the Mid-Ocean Dynamics Experiment (MODE) southwest of Bermuda, Bruce and Firing [1974] observed under light winds $(2-4 \mathrm{~m} / \mathrm{s})$ a shallow $1-$ to $2-\mathrm{m}$ layer that was $2^{\circ}-3^{\circ} \mathrm{C}$ warmer than the main mixed layer. In the eastern Atlantic, near the African coast, at $21^{\circ} 40^{\prime} \mathrm{N}$, Halpern and Reed [1976] found diurnal sea surface warming of up to $1.4^{\circ} \mathrm{C}$ in March 1972.

Satellite thermal infrared measurements, which on occasion show large diurnal signals, have been suspect because in situ temperature measurements for calibration were lacking. Deschamps and Frouin [1984] used satellite data to show diurnal warming in the Mediterranean Sea, but they had no in situ data with which to verify their observations. Lynn and Siejkotsky [1984] compared satellite and in situ data for two days in late November and found that the in situ observations differed significantly from the satellite observations.

Stramma et al. [1985], using in situ data and model results, demonstrated conclusively that large diurnal warming seen in satellite-derived SST fields represents quite accurately warming in the upper $1 \mathrm{~m}$ or so of the water column. They observed diurnal signals of up to $3.5^{\circ} \mathrm{C}$ from satellite data, in excellent agreement with a thermistor at $0.6 \mathrm{~m}$ on a 2-year mooring. Both results from a one-dimensional modcl and coincident synoptic meteorological obscrvations verify that such events result from low wind spccds and high solar insolation. The area of diurnal warming in excess of $1^{\circ} \mathrm{C}$ was shown to exceed $300,000 \mathrm{~km}^{2}$ on occasion. Furthermore, it appears from their data that the influencc on such events of the cool surface skin in the top several micrometers of the water column is small. Stramma et al.'s [1985] investigation was restricted to events

Copyright 1985 by the American Geophysical Union.

Paper number 5 C0554.

$0148-0227 / 85 / 005 C-0554 \$ 05.00$ observed in the mooring temperature record at $34^{\circ} \mathrm{N}, 70^{\circ} \mathrm{W}$. Since the comparison with mooring data shows that the satellite data are a reliable measure of sea surface warming in excess of $0.5^{\circ} \mathrm{C}$, we extended the study from the vicinity of the mooring to a larger area in the western North Atlantic Ocean to show the spatial distribution of large diurnal warming events as well as the change in this distribution through the summer. In addition, a comparison is made between the distributions of warming events in the summers of 1982 and 1983, and the influence of large horizontal warming events on the atmosphere-ocean heat exchange computed from bulk formulae is investigated.

\section{Satellite Data Processing}

A description of the steps involved in processing the satellite data is given in Figure 1. Dashed lines between steps indicate that all of the satellite passes were processed through the previous step before preceding to the next one. All but one of the steps were automated. This was necessary because of the large volume of data handled, over 1000 passes for the two summers.

Because of the superior SST retrievals possible from an instrument with two spectral channels in the 10-12 $\mu \mathrm{m}$ atmospheric window over those with only one channel [McMillin and Crosby, 1984], only data from the NOAA-7-borne advanced very high resolution radiometer (AVHRR) were used. Every NOAA 7 pass covering the western Sargasso Sea for the months of expected large diurnal warming (April through September) in 1982 and 1983 was read into the computer (step 1 in Figure 1); decimated by four, keeping every fourth pixel and every fourth scan line (step 2); and atmospherically corrected, using the NOAA/NESDIS [1982] two-channel algorithm (step 3). Steps 1 through 3 were performed at the University of Miami by $\mathrm{O}$. Brown, R. Evans, and J. Brown.

In the first pass through the data it was found that the SST values at large scan angles were depressed by up to $3^{\circ} \mathrm{C}$. This effect is referred to as limb darkening and results from the significantly longer atmospheric path length at these angles when compared to the path length at nadir, straight down. Because the ground track of the satellite varies from one pass to the ncxt and becausc day and night passes are subtracted to obtain areas of diurnal warming, limb darkening may give rise 


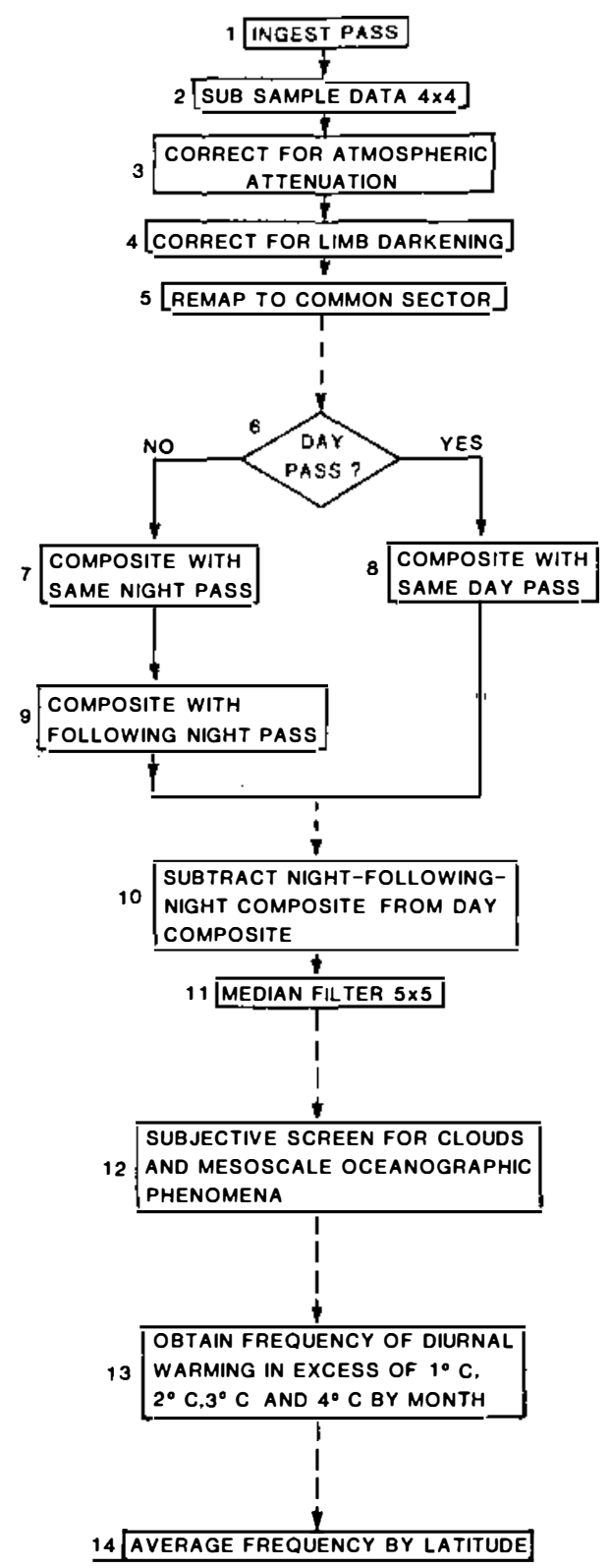

Fig. 1. Processing sequence for the satellite data.

to apparent warming or cooling, depending on which pass, day or night, makes use of data at the swath edge. It was therefore necessary to compensate for limb darkening (step 4 in Figure 1) to make maximum use of the available data. The simplest equation for making such corrections is

$$
7_{\mathrm{s}}^{\prime}=7_{\mathrm{s}}+\gamma(1 / \cos (\theta)-1)+\xi
$$

where $T_{\mathrm{s}}^{\prime}$ is the corrected $T_{\mathrm{s}}$ value; $T_{\mathrm{s}}$ is the derived surface temperature, assuming no scan angle dependence; $\gamma$ and $\xi$ are constants; and $\theta$ is the angle from the normal to the earth's surface at the pixel of interest. The constants $\gamma$ and $\xi$ were determined by regressing the satellite-derived values on in situ data obtained from a fixed mooring at $34^{\circ} \mathrm{N}, 70^{\circ} \mathrm{W}$. Twohundred twelve comparisons covering the 2-year study period were used. The rms deviation of the satellite-derived SST values about the buoy data was reduced from $1.37^{\circ} \mathrm{C}$ to $0.51^{\circ} \mathrm{C}$, using this equation with regression values of $\gamma=$ -2.172 and $\xi=0.623$.

The data were then remapped (step 5) to a coordinate system rectangular in longitude and latitude and extending from $17^{\circ}$ to $40^{\circ} \mathrm{N}$ and from $55^{\circ}$ to $80^{\circ} \mathrm{W}$, with each pixel representing approximately $23.5 \mathrm{~km}^{2}$. The remapped data were composited into day and night images (steps 6-8). A daytime composite was made by combining the two images generally covering the area during daytime hours such that any pixel in the resulting image consisted of the warmest of the corresponding pixels from the two images. The nighttime composite was made similarly. Because clouds are usually colder than the sea surface, this step tended to eliminate some of the cloud cover. In the next step (9), nighttime composites were composited in adjacent pairs to further decrease the impact of clouds. The composite of the nighttime data preceding the daytime pass shown in Plate $1 a$ (or Plate $2 a$ ) with the nighttime data following this pass is shown in Plate $1 b$ (or Plate $2 b$ ). The difference (step 10) of the daytime image minus the nighttime pair is shown in Plate $1 c$ (or Plate $2 c$ ). (Plates 1 and 2 can be found in the separate color section in this issue.)

These data were then filtered with a $5 \times 5$ median filter (step 11) and subjectively screened (step 12) by one of the authors for extraneous values. (This screening was the only manual input to the process.) The extraneous values resulted either from noise in the SST data at the edge of clouds or from actual oceanographic phenomena such as displacement of rings or eddies with a strong temperature signature. In the case of cloud contamination the problem in the data was obvious, since such events occur on the periphery of cloud-covered areas; hence the erroneous values were easily removed. Temperature changes resulting from the displacement of mesoscale features were not as easily detected, but they always occur near the Gulf Stream or in coastal waters, so the region from which statistics were derived was constrained to the open ocean and to the south and east of the Gulf Stream. The excluded region is shown as the masked, light grey area on the statistical results (Plates 3-6). (Plates 3-6 can be found in the separate color section in this issue.)

To obtain the statistics on warming (the major focus of this paper), the median-filtered day-night temperature differences were combined into monthly data sets. This was done by summing the number of times that each pixel in the 30 or so difference images in a month showed warming in excess of $1^{\circ}$, $2^{\circ}, 3^{\circ}$, and $4^{\circ} \mathrm{C}$ (step 13). This sum was divided by the number of days for which satellite data existed in both the composite of the nighttime pair and the daytime composite for the given pixel. The result of this step was then a number of images, four for each month studied, showing the fraction of time a given location in the image experienced warming in excess of $1^{\circ}, 2^{2}$, $3^{\circ}$, or $4^{\circ} \mathrm{C}$. In the final step (14) of the analysis one obtains the fraction of time that the pixels at a given latitude showed warming in excess of one of the four selected values.

\section{ObSeRvations}

Two sea surface warming events are presented in Plates 1 and 2. In Plate 1, SST observations of April 28, 1983, are shown. Plate $1 a$ shows the daytime composite image; Plate $1 b$ is the nighttime composite. The shelf water near the coast, shown in blue in Plate $1(a, b)$, is quite cold in April. A strong temperature gradient (green, brown, and yellow) marks the northern edge of the Gulf Stream, which has a large meander interacting with several cold core rings to the south. Southeast of the Gulf Stream, the Sargasso Sea, seen as brown in the center and brown and green (colder) in the northeast, is somewhat cooler than the Gulf Stream. In the south the change to warm tropical water (orange) and larger clouds (white) is visible. The main difference between the daytime and nighttime 
composites is the long feature extending from west southwest to east northeast at about $33^{\circ} \mathrm{N}$. This feature, as defined by the $1^{\circ} \mathrm{C}$ contour, is $1100 \mathrm{~km}$ long and $85 \mathrm{~km}$ wide, with an area of approximately $93,500 \mathrm{~km}^{2}$.

In Plate $1 c$ the unsmoothed day-night difference is shown with colors representing ranges of temperature differences (see caption of Plate $1 c$ for color key). Only in the vicinity of the large east-west feature are there areas with temperature differences in excess of $0.5^{\circ} \mathrm{C}$. All other areas have a day-night temperature difference of less than $0.5^{\circ} \mathrm{C}$ (grey color). The smaller area of apparent warming to the northwest of the main feature is due to Gulf Stream variability. Point observations of apparent diurnal warming scattered throughout the image are attributed to clouds and removed in subsequent processing. In Plate $1 d$ the median-filtered contours of warming of more than $1{ }^{\circ} \mathrm{C}$ have been superimposed on the corresponding weather map [European Meteorological Bulletin, $1982,1983]$. The time of the meteorological observation, 2400 GMT, is about 6 hours later than the time of maximum warming. Wind observations near the area of warming are presented in the figure as arrows (with markings to indicate wind speed; see caption of Plate $1 d$ ). As the geostrophic wind follows the contours of the isobars, the lowest wind speed should be found in the center of the ridge of the 1020-mbar contour. Wind observations from ships verify the predicted wind field. The center of the Atlantic high is located at $45^{\circ} \mathrm{N}$,

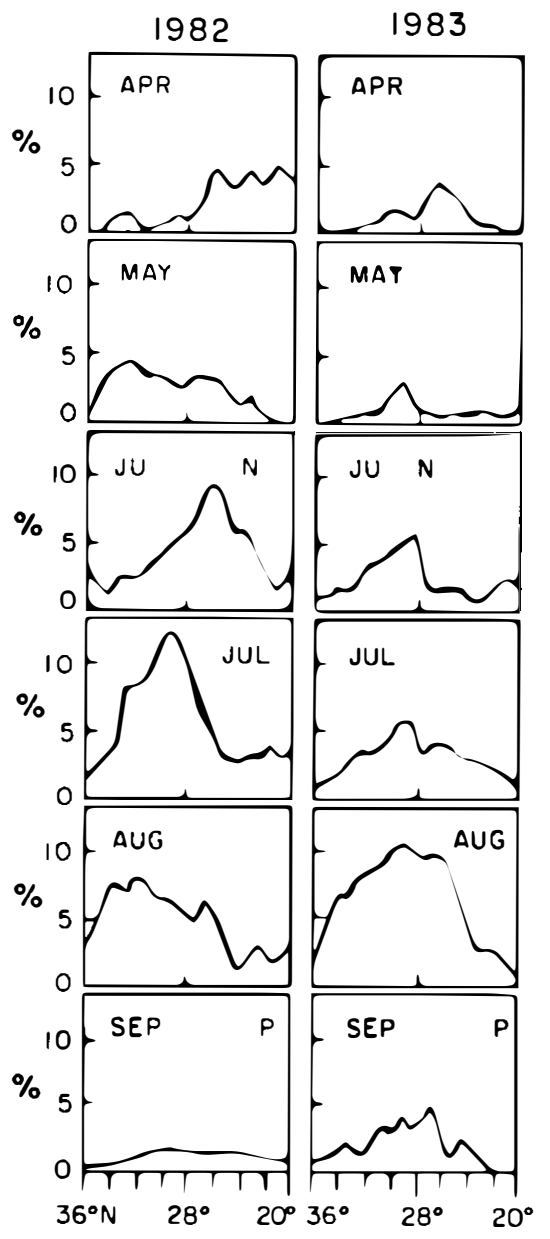

Fig. 2. Mean percent of diurnal warming in excess of $1^{-C}$ versus latitude averaged by longitude for the months of April (top) to September (bottom) of 1982 (left) and 1983 (right). $40^{\circ} \mathrm{W}$. The ridge of the $1020-\mathrm{mbar}$ contour is separated from this high by the cold front with a small low. The contours of diurnal warming derived from the satellite data fit the pressure contours well and indicate the area of the lowest wind velocity.

The SST observations of June 16, 1982, are presented in Plate 2. Plate $2 a$ shows the daytime composite image, Plate $2 b$ the nighttime composite, and Plate $2 c$ the unsmoothed daynight temperature difference of more than $0.5^{\circ} \mathrm{C}$. The ocean is clearly warmer than in late April (Plate $1(a, b)$ ). The area of warming in the east around $28^{\circ} \mathrm{N}$, with a spur at $65^{\circ} \mathrm{W}$ reaching $32^{\circ} \mathrm{N}$, is a darker red in Plate $2 a$ than in Plate $2 b$. The area of warming of more than $1^{\circ} \mathrm{C}$ has a length of about $1000 \mathrm{~km}$ and a width of about $200 \mathrm{~km}$ and is about $200,000 \mathrm{~km}^{2}$. Primarily because of its larger width, diurnal warming between 0.5 and $1.0^{\circ} \mathrm{C}$ (Plate $2 c$ ) covers a much larger area for this event than the event of April 1983 (Plate 1c). The meteorological observations with the satellite-derived contours of warming are shown in Plate $2 d$. The wind observations from ship reports again show the lowest wind speeds in the center of the ridge near the area of heating and stronger winds around this ridge. The circle with the cross at approximately $25^{\circ} \mathrm{N}, 62^{\circ} \mathrm{W}$, just south of the $1^{\circ} \mathrm{C}$ warming contour, is a ship observation reporting no wind. The weather map shows a cold front ending in the area of heating at the center of the ridge. Near this front the satellite observation shows only a few small clouds, but the day-night warming is weaker than in the surrounding area.

The two examples in Plates 1 and 2 show the relationship between the ridge of the Azores-Bermuda high and the area of large $\left(>0.5^{\circ} \mathrm{C}\right)$ diurnal warming. Because this ridge generally has an east-west orientation in the western North Atlantic, the corresponding diurnal warming events also have an east-west orientation. These observations were seen to extend to all other events examined.

\section{DistribUTION OF WARMING EVENTS}

The probability distributions of diurnal warming in excess of $1 \mathrm{C}$ and $2 \mathrm{C}$ are shown by month for the period April through September in both 1982 and 1983: Plate $3\left(1^{\circ} \mathrm{C}\right.$, April-June), Plate $4\left(2 \mathrm{C}\right.$, April-June), Plate $5\left(1^{\circ} \mathrm{C}\right.$, JulySeptember $)$, Plate $6(2 \mathrm{C}$, July-September $)$. The plots for warming in excess of 3 and $4 \mathrm{C}$ (not presented here) show similar distributions, but with much smaller frequencies. In Plates 3-6, near the edge of the image, the frequency distribution changes abruptly across fairly long straight lines. These changes, which result from day-night pairs that cover only part of the region studied, appear as steps in color. An attempt was made to normalize the data to avoid this problem, but the fairly small number of events in any given month result in these statistical discontinuities. The monthly mean percentage of warming events in excess of $1 \mathrm{C}$ as a function of latitude averaged over longitude is presented in Figure 2. The corresponding plots for warming in excess of $2 \mathrm{C}$ are presented in Figure 3.

Three observations are readily apparent in these figures. First, the highest probability of warming occurs in the months of June, July, and August. The reason for this is that, in these months. at these latitudes the shortwave radiation incident on the earth's surface on a cloudless day is near its maximum [Kondratyer, 1969], as are the frequency of wind speeds of less than $5 \mathrm{~m} / \mathrm{s}$ and the frequency of total cloud cover of less than two eighths [U.S. Navy, 1974]. For the area investigated here, the frequency of wind speeds of less than $5 \mathrm{~m} / \mathrm{s}$ in April is $60 \%$ 


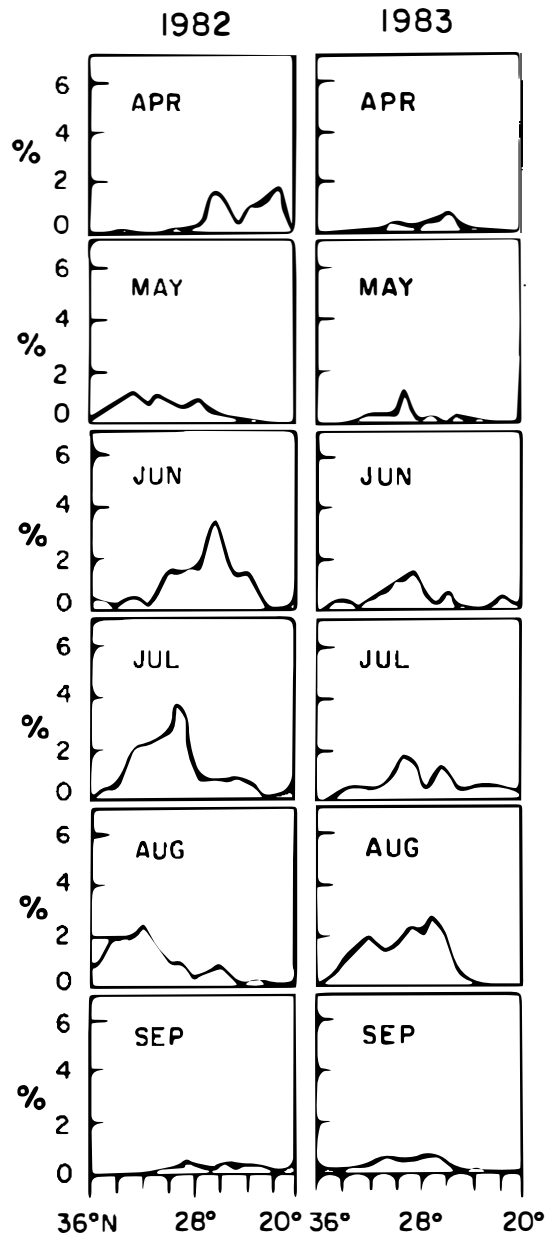

Fig. 3. Mean percent of diurnal warming as in Figure 2, but for warming in excess of $2^{\circ} \mathrm{C}$.

in the east and between $40 \%$ and $60 \%$ elsewhere [U.S. Navy, 1974]. These frequencies are $60 \%-80 \%$ in July (about $20 \%$ higher than in April) and decrease to about $60 \%$ for a large part of the area in September. For cloud cover of less than two eighths, the change in frequency is smaller than the frequency change for wind speed. The values increase from $30 \%$ south of $30^{\circ} \mathrm{N}$ in April to $40 \%$ near $30^{\circ} \mathrm{N}$ in July and decrease to $30 \%$ east of $70^{\circ} \mathrm{W}$ in September [U.S. Navy, 1974]. From the data presented in Plates 3-6 it can be seen that at some locations the frequency of diurnal warming in excess of $1{ }^{\circ} \mathrm{C}$ (Plates 3 and 5) reaches a maximum of about $30 \%$ in June, July, and August. The probability of warming in excess of $1^{\circ} \mathrm{C}$, averaged over longitude from $55^{\circ} \mathrm{W}$ to the edge of the grey mask, reaches a maximum of $12.8 \%$ in July 1982 (Figure 2). The distributions for frequency of occurrence in excess of $3^{\circ}$ and $4^{\circ} \mathrm{C}$, not shown here, are similar to those for $1^{\circ}$ and $2^{\circ} \mathrm{C}$ events both geographically and in their temporal evolution. The only diffierence is in the magnitude of the distribution, which for $3^{\circ} \mathrm{C}$ and greater events has a maximum of $1 \%$ and for $4^{\circ} \mathrm{C}$ and greater has a maximum of $0.2 \%$.

The second observation derived from Plates 3-6 and Figures 2 and 3 is the seasonal change in the latitude of maximum warming. From spring to summer the area with the largest frequency of warming shifts from $25^{\circ} \mathrm{N}$ in April to $33^{\circ} \mathrm{N}$ in August and back to the south in September. An investigation of the frequency of wind speeds of less than $5 \mathrm{~m} / \mathrm{s}$ as well as the frequency of cloud cover of less than two eighths
[U. S. Navy, 1974] shows that, in the area investigated, exactly the same shift from $25^{\circ} \mathrm{N}$ in spring to approximately $30^{\circ} \mathrm{N}$ in summer and back to the south in September occurs for both frequencies. This again shows the close relation between meteorological parameters and large diurnal warming events.

The third observation relates to the difference between the two years studied. For diurnal warming in excess of $1^{\circ} \mathrm{C}$ the south-north-south cyclical shift in frequencies for the summer half-year (Figures 2 and 3) is more evident in 1982 than in 1983. Warming events between April and July were observed more of ten in 1982 than in 1983, while in August and September these events were observed more often in 1983 than in 1982. The maximum percentage for 1982 is observed in July (Figure 2) and for 1983 in August (Figure 3). These differences result from regional differences in the percent cloud cover determined from the AVHRR data for each of the two years. For example, in July 1982 there was very little $(<20 \%)$ cloud cover south of $30^{\circ} \mathrm{N}$, while in 1983 the mean cloud cover for the month was substantially higher than $20 \%$ in the same region. North of $32^{\circ} \mathrm{N}$, the two years showed a similar probability of cloud cover for July. The differences in percent cloud cover in July between the two years account for the difference in the shapes of the corresponding curves shown in Figures 2 and 3. Similar arguments apply to differences in the curves for the other months. These data suggest that the onset of large diurnal warming (and most probably other quantities related to heat flux through the air-sea interface) was delayed by approximately 1 month in 1983 relative to 1982 as a result of extensive cloud cover in 1983. This, coupled with the fact that large diurnal warming events did not continue much later into the fall in 1983 than in 1982, further suggests a relatively shorter period of warming in 1983

\section{Impact of Diurnal Warming on Air-Sea Heat Exchange}

The net air-sea heat flux is a critical variable in numerical models of global climate. A number of different parameterizations of the bulk formulae [Talley, 1984] have been used to calculate this flux. In all parameterizations the three processes leading to a loss of heat from the ocean depend on the SST, and an increased loss of heat occurs with an increase in SST, all other variables being held constant. Calculations of the net air-sea heat flux made to date have used ship-derived SST values, which in fact are generally obtained at least $1 \mathrm{~m}$ below the surface and are thus a measure of the mixed layer temperature and not the true SST. Stramma et al. [1985] have shown that this can result in significant underestimates of the SST on days for which large diurnal warming events occur. For example, for the month of July 1982 at $34^{\circ} \mathrm{N}, 70^{\circ} \mathrm{W}$, Stramma et al. obtained a mean day-night temperature difference of $0.4^{\circ} \mathrm{C}$ at $0.6 \mathrm{~m}$. Thus, averaged over the month, the mixed-layer temperature, which does not include the diurnal warming events, was at least $0.2^{\circ} \mathrm{C}$ cooler than the actual SST.

Given the importance of the air-sea heat flux, its dependence on the SST, and the fact that diurnal warming events have not been properly included in heat flux calculations made to date, an estimate of the impact of such events on the net heat flux is included here. We use the bulk formulae of Molinari et al. [1985], compute the vapor pressure and wet bulb temperature from equations given by Abbott and Tabony [1985], and use Kondratyev's [1969] table for shortwave radiation. All other input variables, except SST, are derived from ship observations near warming events. Performing the heat flux calculation with a typical mixed-layer temperature for the region and then repeating the calculation for a temperature 
$0.2^{\circ} \mathrm{C}$ higher yields a decrease of $5 \mathrm{~W} / \mathrm{m}^{2}$ in the heat flux entering the ocean. Although this decrease is well within the errors quoted for the heat flux calculations [Esbensen and Reynolds, 1981], several comments are appropriate. First, from the statistics on warming events presented in this paper, such losses will occur over fairly large $\left(\sim 10^{\circ}\right.$ of latitude by $\sim 10^{\circ}$ of longitude) areas in the ocean. Second, regardless of the parameterization used, the losses are always of the same sign. Third, heat loss has been averaged over a month; the losses over a 24-hour period, including a large warming event, will be substantially larger. Fourth, averaging the temperature differences over 1 month tends to underestimate the actual heat loss because the dependence on SST is at least linear and in the case of long-wave losses is a power of 4.

\section{Discussion and Conclusions}

Satellite data from April through September 1982 and 1983 were used in the western North Atlantic to investigate the distribution of large diurnal warming events. The largest frequency of warming is found near $25^{\circ} \mathrm{N}$ in the spring and fall and near $30^{\circ} \mathrm{N}$ in the summer. Large diurnal warming events are related to the westward extent of the ridge associated with the Azores-Bermuda high, which is generally an area of low wind speeds. Sandwell and Agreen [1984] used nearly 4 years of GEOS 3 altimeter data to compute surface wind speeds over most of the world ocean. For the summer period (June to September) they found the lowest wind speeds in the western Sargasso Sea near $30^{\circ} \mathrm{N}$. Their contours of low wind speeds fit well the area with the largest number of warming events found here. The south-north-south cycle of the maximum frequency of such events follows closely the same shift in the maximum frequency of wind speeds of less than $5 \mathrm{~m} / \mathrm{s}$ and the maximum frequency of total cloud cover of less than two eighths [U.S. $N a v y, 1974]$. Although the general meridional shift in the distribution was similar from one year to the next, 1983 shows a much later onset in the number of large warming events than does 1982.

In selected areas during the summer months, diurnal warming in excess of $1{ }^{\circ} \mathrm{C}$ occurred approximately $30 \%$ of the time. Averaged over an approximately $1600-\mathrm{km}$ range in longitude, the frequency of occurrence of diurnal warming in excess of $1{ }^{\circ} \mathrm{C}$ reached a maximum of $12.8 \%$ at $30^{\circ} \mathrm{N}$. From these findings it is surprising that large diurnal warming events had been observed so rarely in the past. From Sandwell and Agreen's [1984] estimated wind field it follows that large diurnal warming should be expected over large areas of the world ocean.

The United States Navy currently has an ocean thermal model in which diurnal surface temperature diffierences of more than $0.5^{\circ} \mathrm{C}$ in large areas of the world ocean are forecast (R. M. Clancy, personal communication, 1985). A comparison of the model predictions with satellite observations is planned to provide a measure of the model's accuracy while at the same time allowing an investigation of diurnal warming on a global scale.

Simple computations of air-sea heat exchange show that diurnal warming has only a small impact on the monthly mean air-sea heat flux, but the impact is always biased in the same direction, toward a lower net heat flux into the ocean.
Furthermore, this is true regardless of the parameterization used for the bulk formulae. These computations also show that the local sun time of the satellite pass must be taken into account if satellite-derived SST values are to be used in heat flux calculations. Data taken only from daytime passes will give estimates of the mean heat flux into the ocean that are too low, while nighttime passes will tend to give estimates that are too high, matching the high bias resulting from the use of ship data.

Acknowledgment. This research has been supported by the Office of Naval Research through contract N00014-81-C-0062. The image processing software was developed by O. Brown, R. Evans, J. Brown, and $\mathrm{A}$. Li at the University of Miami with Office of Naval Research funding. The continuing support of the Miami group is gratefully acknowledged.

\section{REFERENCES}

Abbott, P. F., and R. C. Tabony, The estimation of humidity parameters, Meteorol. Mag., 114, 49-55, 1985.

Bruce, J. G., and E. Firing, Temperature measurements in the upper $10 \mathrm{~m}$ with modified expendable bathythermograph probes, J. Geophys. Res., 79, 4110-4111, 1974.

Deschamps, P. Y., and R. Frouin, Large diurnal heating of the sea surface observed by the HCMR experiment, J. Phys. Oceanogr., 14 177-184, 1984.

Esbensen, S. K., and R. W. Reynolds, Estimating monthly averaged air-sea transfers of heat and momentum using the bulk aerodynamic method, J. Phys. Oceanogr., 11, 457-465, 1981.

European Meteorological Bulletin, diurnal maps, Dtsch. Wetterdienst Zent., Off enbach, Fed. Repub. Ger., 1982, 1983.

Halpern, D., and R. K. Reed, Heat budget of the upper ocean under light winds, J. Phys. Oceanogr., 6, 972-975, 1976.

Kaiser, J. A. C., Heat balance of the upper ocean under light winds, $J$. Phys. Oceanogr., 8, 1-12, 1978.

Kondratyev, K. Ya., Radiation in the Atmosphere, 912 pp., Academic, New York, 1969.

Lynn, R. J., and J. Svejkovsky, Remotely sensed sea surface variability off California during a "Santa Ana" clearing, J. Geophys. Res., 89, $8151-8162,1984$.

McMillin, L. M., and D. S. Crosby, Theory and validation of the multiple window sea surface temperature technique, J. Geophys. Res., 89, 3655-3661, 1984.

Molinari, R. L., J. F. Festa, and E. Marmolejo, Evolution of seasurface temperature and surface meteorological fields in the Tropical Atlantic Ocean during FGGE, 1979: 1, Description of surface fields and computation of surface energy fluxes, Progr. Oceanogr., $14,401-420,1985$.

NOAA/NESDIS, Coefficients presented at the 32nd SST Research Panel Meeting, Nat. Environ. Sat., Data, Inf. Ser., Nat. Oceanic Atmos. Admin., Suitland, Md., September 30, 1982.

Sandwell, D. T., and R. W. Agreen, Seasonal variation in wind speed and sea state from global satellite measurements, J. Geophys. Res., 89, 2041-2051, 1984.

Stramma, L., P. Cornillon, R. A. Weller, J. F. Price, and M. G. Briscoe, Large diurnal sea surface temperature variability: satellite and in situ measurements, J. Phys. Oceanogr., in press, 1985.

Talley, L. D., Meridional heat transport in the Pacific Ocean, J. Phys. Oceanogr., 14, 231-241, 1984

U. S. Navy, Marine Climatic Atlas of the World, vol. 1, North Atlantic Ocean (revised 1974), NAVAER 50-1C-528, 371 pp., U. S. Government Printing Office, Washington, D. C., 1974.

P. Cornillon \& L. Stramma, Graduate School of Oceanography, University of Rhode Island, Narragansett, RI 02882.

(Received May 15, 1985; accepted June 5, 1985.) 